\title{
An Axial Foilless Diode Guided by Composite Magnetic Field for the Production of Relativistic Electron Beams
}

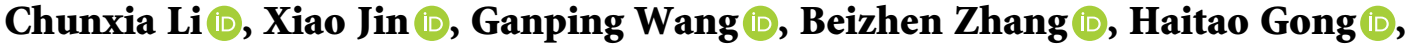 \\ Yanqing Gan $\mathbb{D}^{D}$, Fei Li $\mathbb{D}^{\mathbb{D}}$, and Falun Song $\mathbb{i}$
}

\begin{abstract}
Science and Technology on High Power Microwave Laboratory, Institute of Applied Electronics, China Academy of Engineering Physics, Mianyang 621900, China
\end{abstract}

Correspondence should be addressed to Falun Song; songfalun@caep.cn

Received 29 July 2020; Accepted 2 February 2021; Published 17 February 2021

Academic Editor: Dieter H.H. Hoffmann

Copyright (c) 2021 Chunxia Li et al. This is an open access article distributed under the Creative Commons Attribution License, which permits unrestricted use, distribution, and reproduction in any medium, provided the original work is properly cited.

Foilless diode are widely used in high-power microwave devices, but the traditional foilless diodes have large volume, heavy weight, and high power consumption, which are not conducive to the application of high-power microwave system on mobile platform. In order to reduce the size of the foilless diode, improve the transmission efficiency of electron beams, and reduce the weight and power consumption of the guiding magnetic field system, an axial foilless diode with a composite guiding magnetic field system is developed in this paper. By adjusting the structure size and magnetic field parameters of solenoid coil, permanent magnet, and soft magnet, the configuration of the composite magnetic field is optimized. The diameter of the anode tube is about $40 \%$ smaller than that of the original structure, and the weight and power consumption of the guiding magnetic system are about $40 \%$ lower than that of the original system when the same axial magnetic field intensity in the uniform region is generated. When the magnetic field strength of the permanent magnet is set as $1.4 \mathrm{~T}$ and that of the solenoid coil is in the range of $0.5 \mathrm{~T} \sim 1 \mathrm{~T}$, the electron beam transmission efficiency is $100 \%$, and the diode impedance is adjustable in the range of $100 \Omega \sim 240 \Omega$. The experimental results verify the correctness of the simulation analysis. The experimental results show that when the magnetic field strength of the solenoid coil is $0.98 \mathrm{~T}(0.5 \mathrm{~T})$ and that of the permanent magnet is $1.4 \mathrm{~T}$, the transmission efficiency of the highcurrent annular electron beam with a peak voltage of $636 \mathrm{kV}(590 \mathrm{kV})$ and a peak current of $3.3 \mathrm{kA}(2.6 \mathrm{kA})$ is $100 \%$, and the diode impedance is about $194 \Omega(220 \Omega)$.

\section{Introduction}

Foilless diode is widely used in high-power microwave generation [1-3], free-electron lasers [4], and magnetically confined plasma heating [5]. Since Friedman and Ury developed an electron beam injection gun guided by external magnetic field in 1970 [6, 7], extensive work has been done in the past 50 years in producing high-power relativistic annular electron beams [8-12]. The electron beam produced by foilless diode is usually highly annular, and its space-charge limited current is much higher than that of solid beam, which means that higher current can be transported in vacuum $[13,14]$. Therefore, foilless diodes are well capable of high-power density, long pulsed, and repetitive operated applications, such as high-power microwave devices and microsecond pulse electron accelerators [9].

The axial foilless diodes immersed in solenoid magnetic field are widely used in O-type high-power microwave devices [15-18], as shown in Figure 1. The advantage of the structure is that the diode cathode is completely immersed in the uniform strong magnetic field of solenoid coil, which is conducive to the generation of high-quality annular electron beams. In the development of high-power microwave system, low power consumption and miniaturization are important conditions for the practical application [19-21]. However, the traditional foilless diode structure has the following disadvantages [17, 22-24]: (a) in order to avoid excessive radial electric field, the radius of drift tube is usually large, which makes the size of inner wall of solenoid 
coil much larger than that of microwave device and drift tube, resulting in waste of excitation space; (b) if the diode is to be further miniaturized, it is necessary to reduce the distance between diode cathode and drift tube wall, and this change will lead to the enhancement of the electric field intensity on the cathode emitter, which is very easy to cause the radial emission of electrons on the cathode, thus causing the loss of electron energy. Some electrons even form reverse motion, bombarding the insulator and damaging the insulation system [22]; (c) moreover, the volume, weight, and energy consumption of solenoid coil and auxiliary power equipment are large, which is not conducive to the application on mobile platforms.

In order to reduce the size of the foilless diode, improve the transmission efficiency of electron beam, and reduce the weight and power consumption of the guiding magnetic field system, a new type of axial foilless diode with a composite guiding magnetic field system is developed in this paper. The simulated and experimental results are believed to lay the foundation for the miniaturization, lightweight, and low power consumption of high-power microwave system.

\section{Design of an Axial Foilless Diode with Composite Magnetic Field System}

2.1. Structure Design of the Foilless Diode. The structure of miniaturized foilless diode guided by a composite magnetic field system is shown in Figure 2. The composite magnetic field system is mainly composed of solenoid coil, permanent magnet, and soft magnet. The inner radius, outer radius, and axial length of the solenoid coil are $47.5 \mathrm{~mm}, 168.5 \mathrm{~mm}$, and $400 \mathrm{~mm}$, respectively, and the ampere-turns of the solenoid coil is 315,000 . The soft magnet material is steel Q235. The permanent magnet is made of sintered Nd-Fe-B with magnet brand N48, and its outer surface is coated with stainless steel 304, which has the functions of fixing and protecting permanent magnet, blocking electron bombardment, and preventing corrosion of permanent magnet material.

The main features of the new axial foilless diode are as follows: the emission cathode is set outside the central hole of solenoid coil so that the size of the inner wall of solenoid coil and the excitation space can be reduced, and also the volume and weight of the solenoid coil and its auxiliary equipment can be reduced. Furthermore, the electric field strength on the cathode can also be effectively reduced, which greatly reduces the probability of radial electron emission, avoids unnecessary energy loss, and reduces the risk of insulation failure caused by return electrons [22]. In order to increase the magnetic field intensity in the cathode emission region, a permanent magnet is set outside the cathode rod. In addition, the cathode rod is made of soft magnetic material, which can further improve the magnetic field strength in the cathode emission region by using its function of gathering magnetic field, so as to optimize the magnetic field distribution between the cathode and the anode (A-K gap).
2.2. Design of the Composite Magnetic Field System. In order to study the influence of soft magnet structure layout on magnetic field intensity distribution, five kinds of soft magnet structure layout are designed, as shown in Figure 3. The distributions of axial magnetic field intensity are presented in Figure 4. The simulated results show that the distribution of magnetic field intensity in cathode emission region is greatly affected by different soft magnetic structures. The closer the soft magnet is to the cathode emitter is, the higher the magnetic field intensity is, as shown in Figure 4. However, if the soft magnet is too close to the cathode emitter (as shown in Figures 3(c) and 3(e)), the magnetic field intensity changes dramatically in the A-K region: the magnetic field near the cathode emitter is very strong but decreases rapidly in the direction of electron beam transmission and then increases slowly, as shown in curves (c) and (e) in Figure 4. Such magnetic field configurations will cause the electron beam to vibrate violently, which is not conducive to the high-efficiency interaction between the electron beam and the microwave cavity. In comparison, the structure model shown in Figure 3(a) is the optimal arrangement of soft magnet, and its magnetic field configuration shown in curve (a) in Figure 4 can not only obtain high magnetic field intensity in the $\mathrm{A}-\mathrm{K}$ region but also ensure the stable transmission of electron beam.

Based on the composite magnetic field structure in Figure 3(a), the influence of different radial sizes of permanent magnet on the axial magnetic field intensity distribution is studied with a magnetic field strength of solenoid coil $1 \mathrm{~T}$ and that of permanent magnet $1.4 \mathrm{~T}$, as shown in Figure 5. It can be seen that the radial size of permanent magnet has little effect on the axial magnetic field intensity distribution. And also, the influence of the permanent magnet magnetic field strength on the axial magnetic field intensity distribution is presented, as shown in Figure 6, and the magnetic field strength of solenoid coil is set as $1 \mathrm{~T}$. It can be seen that, with the increase in magnetic field strength of permanent magnet, the magnetic field strength in the A-K region increases stably, which benefits electron beam transmission. The influence of the magnetic field strength of solenoid coil on the axial magnetic field intensity distribution is presented, as shown in Figure 7, and the magnetic field strength of the permanent magnet is set as $1.4 \mathrm{~T}$. It can be seen that the magnetic field strength in the A-K region and the drift tube increases significantly, and the growth rate of magnetic field intensity in drift tube region is faster than that in $\mathrm{A}-\mathrm{K}$ region. When the magnetic field strength of solenoid coil is too large, the magnetic field intensity in the drift tube area is far greater than that in the A-K region, and the uniformity of magnetic field intensity along electron beam transmission path becomes worse, which is not conducive to the full utilization of solenoid coil energy storage. In order to reduce the energy consumption and the weight of the solenoid coil, the magnetic field strength of solenoid coil is set in the range of $0.5 \mathrm{~T}$ to $1.0 \mathrm{~T}$, which has a better efficiency cost ratio.

Figure 8 presents the axial distribution of magnetic field intensity in the diode with three types of magnetic field system. The results show that the distribution of magnetic field strength and the uniformity in the $\mathrm{A}-\mathrm{K}$ region are improved significantly when the soft magnet is applied. 


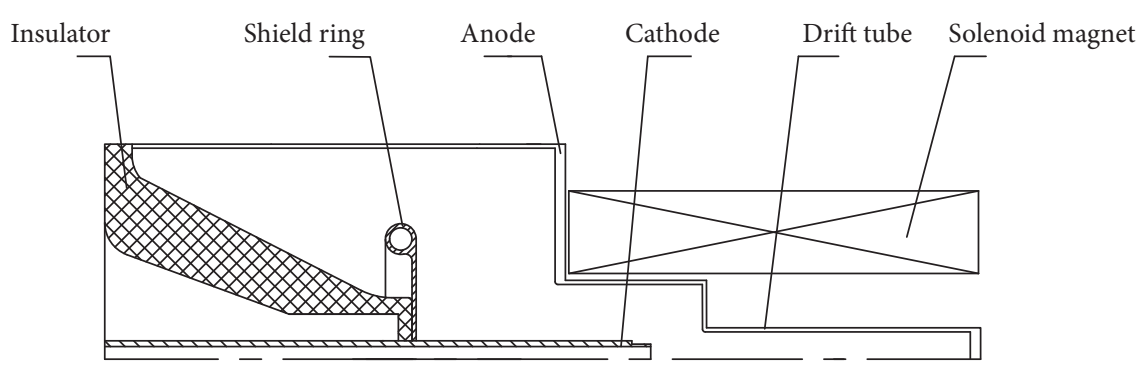

Figure 1: Schematic of a typical foilless diode with solenoid coil magnetic field system.

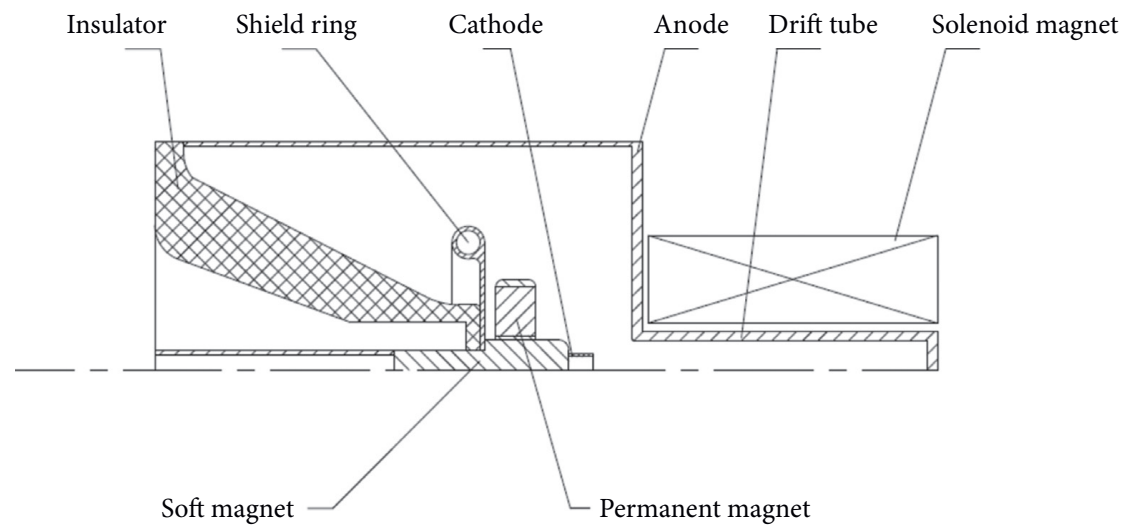

FIgURE 2: Schematic of a compact foilless diode with a composite magnetic system (solenoid coil, permanent magnet, and soft magnet).

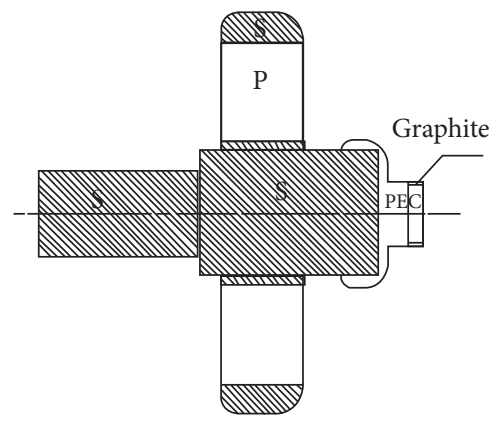

(a)

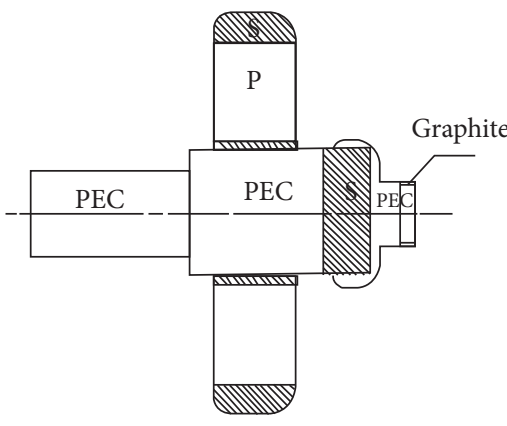

(b)

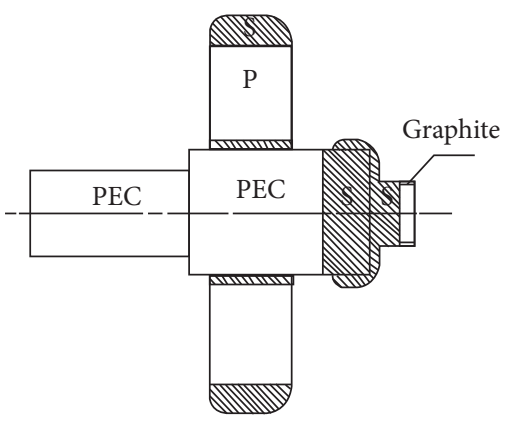

(c)

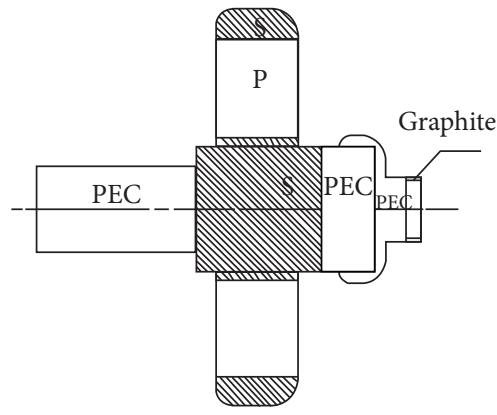

(d)

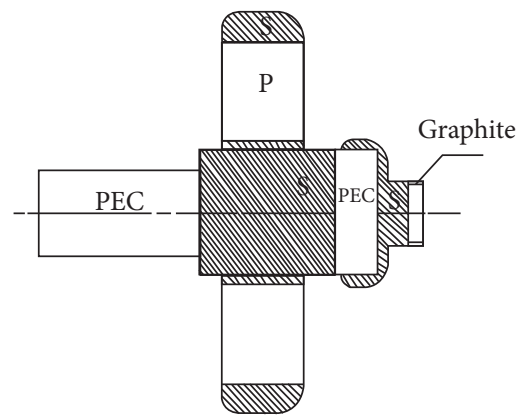

(e)

FIGURE 3: Five kinds of soft magnet structure layout. P for permanent magnet; $S$ for soft magnet.

Magnetic field strength of solenoid coil plays a decisive role in guiding magnetic field strength along the electron beam transmission path, while permanent magnet and soft magnetic field play an important complementary role in magnetic field strength in the A-K region.
2.3. Calculation of Weight and Power Consumption. Table 1 shows the parameter comparison data of single solenoid coil system and composite magnetic field system. The weight of permanent magnet, soft magnet, and solenoid coil are $14.1 \mathrm{~kg}$, $7.5 \mathrm{~kg}$, and $216 \mathrm{~kg}$, respectively. The power consumption of 


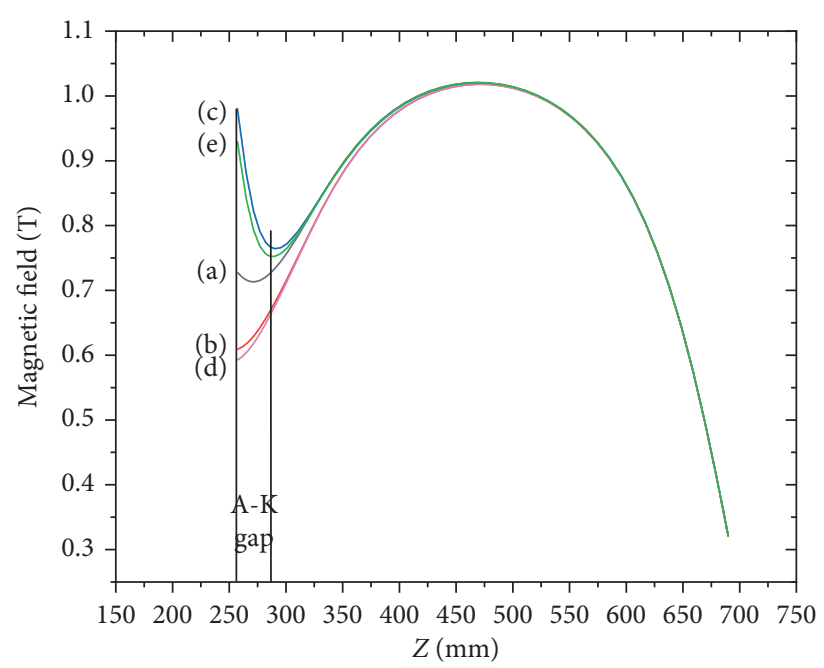

Figure 4: The distribution of composite magnetic field intensity along the axial direction under different arrangements of soft magnetic, as shown in Figure 3. The curves (a), (b), (c), (d), and (e) in this figure correspond to the structure models (a), (b), (c), (d), and (e) in Figure 3, respectively. The magnetic field strength of solenoid coil is $1 \mathrm{~T}$, and that of permanent magnet is $1.4 \mathrm{~T}$.

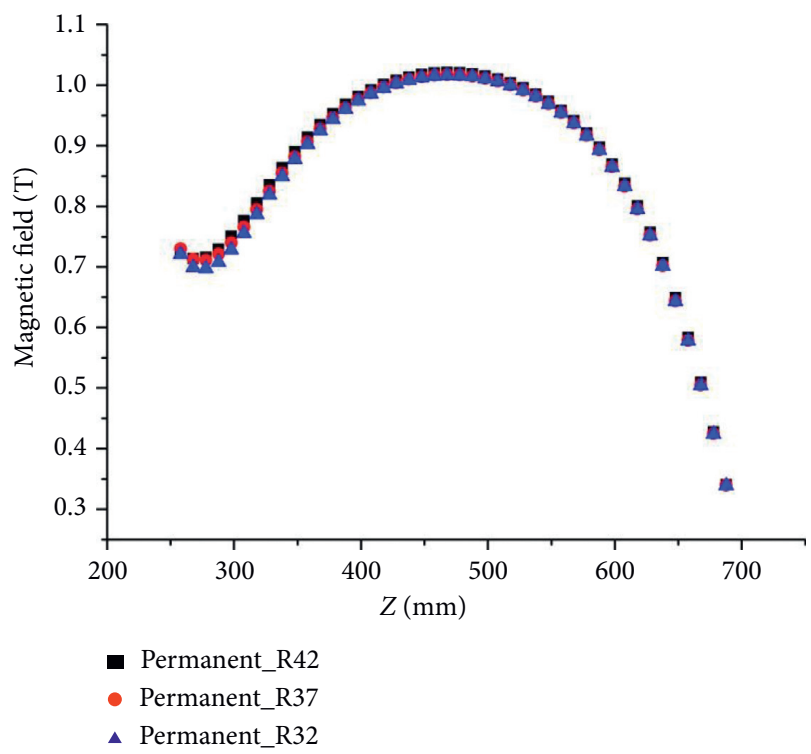

FIGURE 5: The distribution of the composite magnetic field intensity along the axial direction with different radial sizes of the permanent magnet based on the model shown in Figure 3(a). The radii of the permanent magnet are $32 \mathrm{~mm}, 37 \mathrm{~mm}$, and $42 \mathrm{~mm}$, respectively; the magnetic field strength of solenoid coil is $1 \mathrm{~T}$; and that of permanent magnet is $1.4 \mathrm{~T}$.

solenoid coil in the composite magnetic field system is about $16 \mathrm{~kW}$. When the traditional solenoid coil magnetic field system (as shown in Figure 1) is used to guide the axial electron beam with the same axial magnetic field intensity, the weight of the corresponding solenoid coil is about $420 \mathrm{~kg}$, and the power consumption is about $30 \mathrm{~kW}$. Compared with the traditional solenoid coil magnetic system, the weight and power consumption of the composite guiding magnetic field system proposed in this paper can be reduced by about $40 \%$.

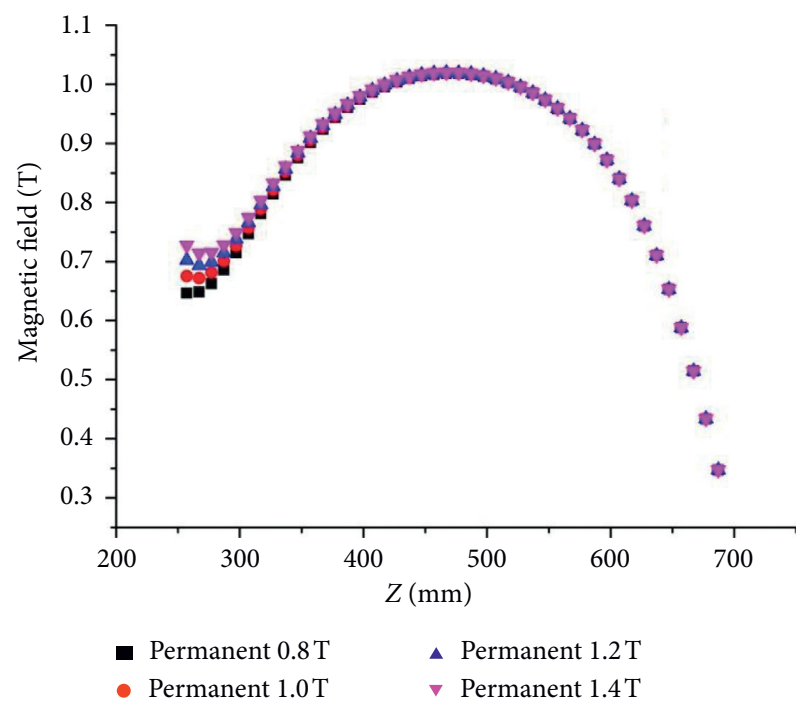

FIGURE 6: The distribution of the composite magnetic field intensity along the axial direction with different permanent magnet magnetic fields based on the model shown in Figure 3(a), and the magnetic field strength of solenoid coil is $1 \mathrm{~T}$.

\section{Analysis of Electron Transmission Efficiency}

Using the composite guiding magnetic field system with permanent magnetic field strength $1.4 \mathrm{~T}$ and that of solenoid coil in the range of $0.5 \mathrm{~T}-1 \mathrm{~T}$, PIC simulation is carried out to obtain the axial electron beam transmission trace. Figure 9 presents the spatial magnetic field intensity distribution. It can be seen that the magnetic field intensity is evenly distributed along the transmission path of the electron beam. The electrons emitted by the cathode can be transmitted 100\% through the drift tube, no electrons are emitted to the drift tube wall, and no return electrons are generated, as shown in Figure 10. The 


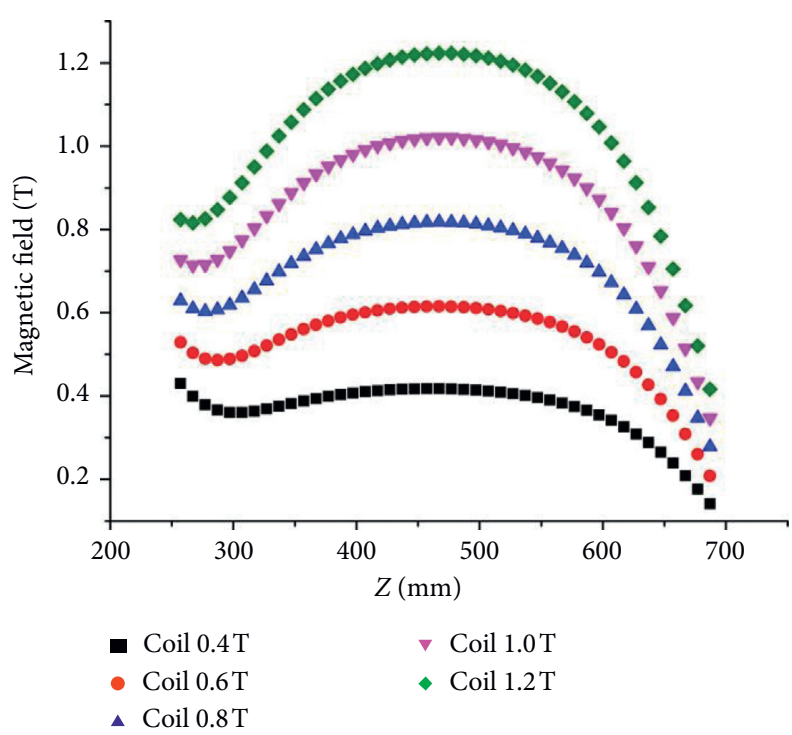

FIGURE 7: The distribution of the composite magnetic field intensity along the axial direction with different magnetic field strengths of solenoid coil based on the model shown in Figure 3(a), and the magnetic field strength of permanent magnet is $1.4 \mathrm{~T}$.

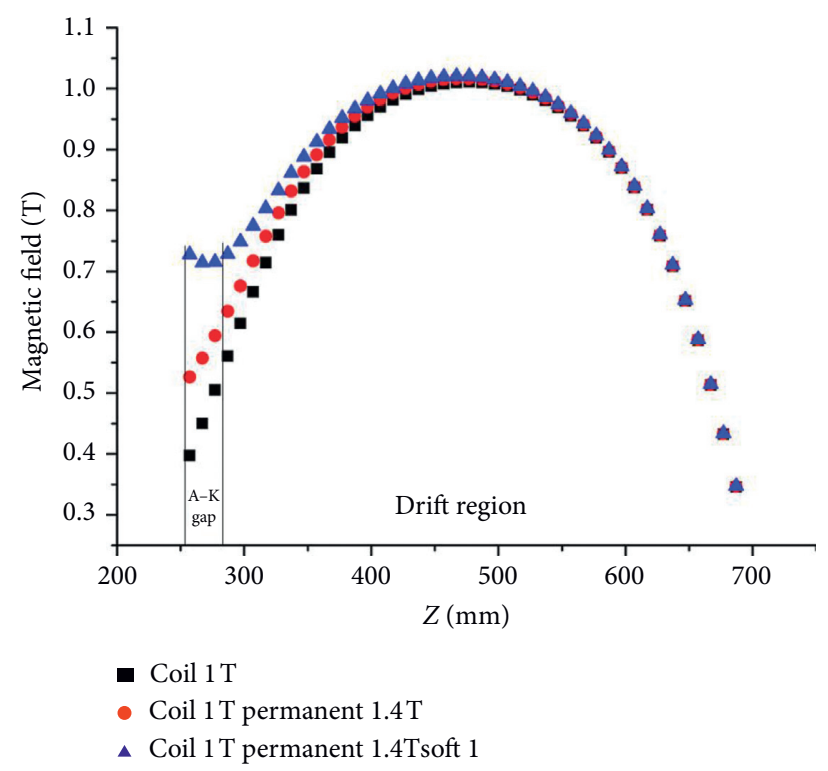

Figure 8: The axial distribution of magnetic field in the diode. (a) Only $1 \mathrm{~T}$ solenoid coil. (b) $1 \mathrm{~T}$ solenoid coil and $1.4 \mathrm{~T}$ permanent magnet. (c) Composite magnetic field system with $1 \mathrm{~T}$ solenoid coil, $1.4 \mathrm{~T}$ permanent magnet, and soft magnet.

electron beam current output waveforms at the transmitter and receiver are presented in Figure 11. It can be seen that the current waveform at the emitter is the same as that at the receiver, and the current amplitude is the same, which proves that the electrons emitted by the annular cathode are transmitted to the receiver $100 \%$.

\section{Experimental Results}

The developed foilless diode with composite magnetic field system is shown in Figure 12. Based on this foilless diode, experimental research was carried out on a compact PFN-Marx pulse power generator [10]. The diode voltage is measured by resistor divider, the total current of diode is measured by B-dot, the current at the end of drift tube is measured by Faraday cylinder, and the arrangement of measurement devices is shown in Figure 13. The experimental results show that, under the condition of solenoid coil magnetic field strength $0.98 \mathrm{~T}$ and permanent magnetic field strength $1.4 \mathrm{~T}$, transmission efficiency of the annular electron beam with voltage $636 \mathrm{kV}(728 \mathrm{kV})$ and current $3.3 \mathrm{kA}(5.7 \mathrm{kA})$ is $100 \%$, and the diode impedance is $194(128) \Omega$. Under the condition of solenoid coil magnetic field strength $0.5 \mathrm{~T}$ and permanent magnetic 
TABLE 1: Comparison between solenoid and composite magnet.

\begin{tabular}{lcccccc}
\hline Magnet type & Inner radius $(\mathrm{mm})$ & Outer radius $(\mathrm{mm})$ & Length $(\mathrm{mm})$ & Volume $(\mathrm{L})$ & Power $(\mathrm{kW})$ & Weight $(\mathrm{kg})$ \\
\hline Solenoid & 151 & 351 & 600 & 70 & 30 & 420 \\
Composite magnet & 95 & 337 & 400 & 36 & 16 & 238 \\
\hline
\end{tabular}

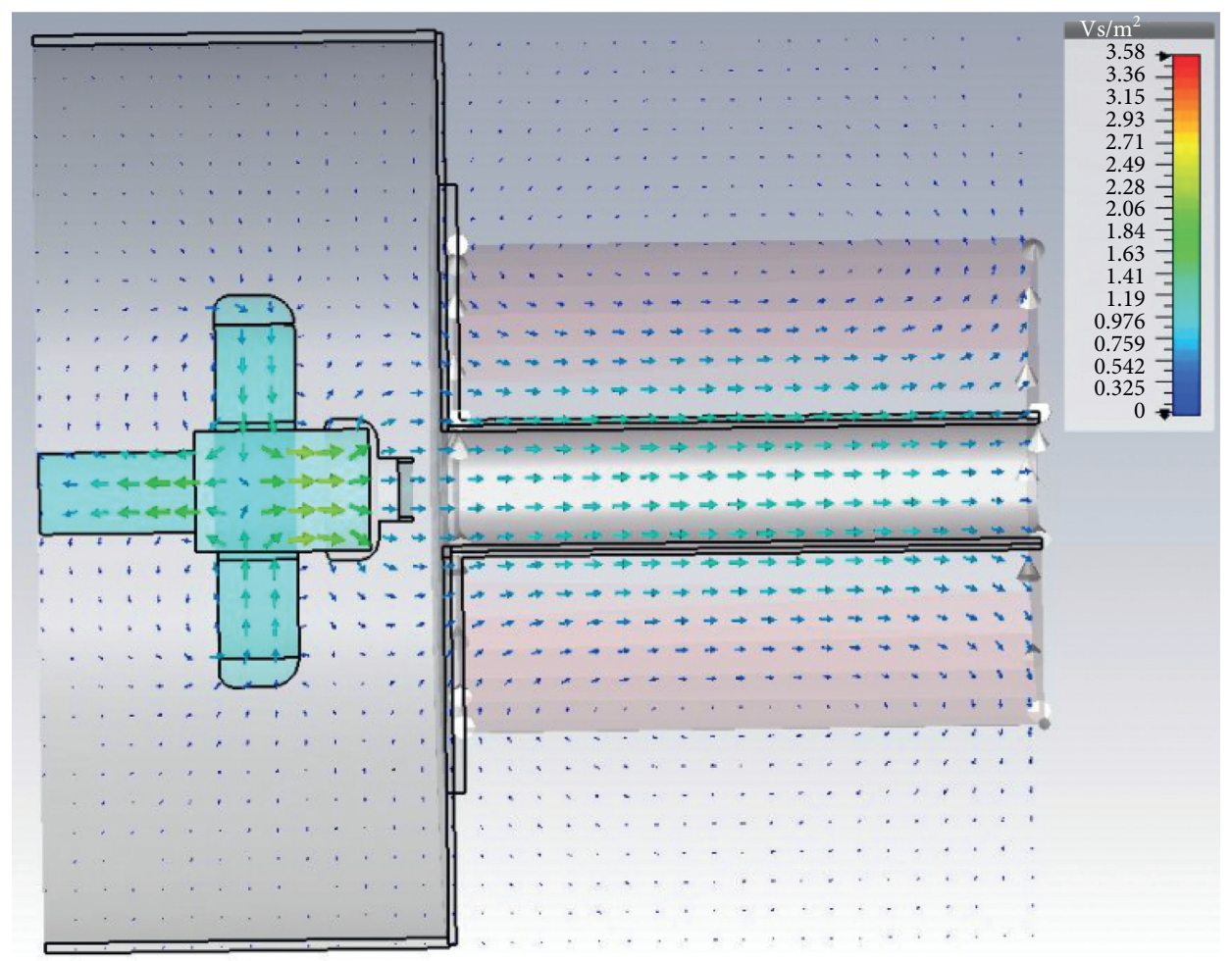

FIgURE 9: The spatial magnetic field intensity distribution.

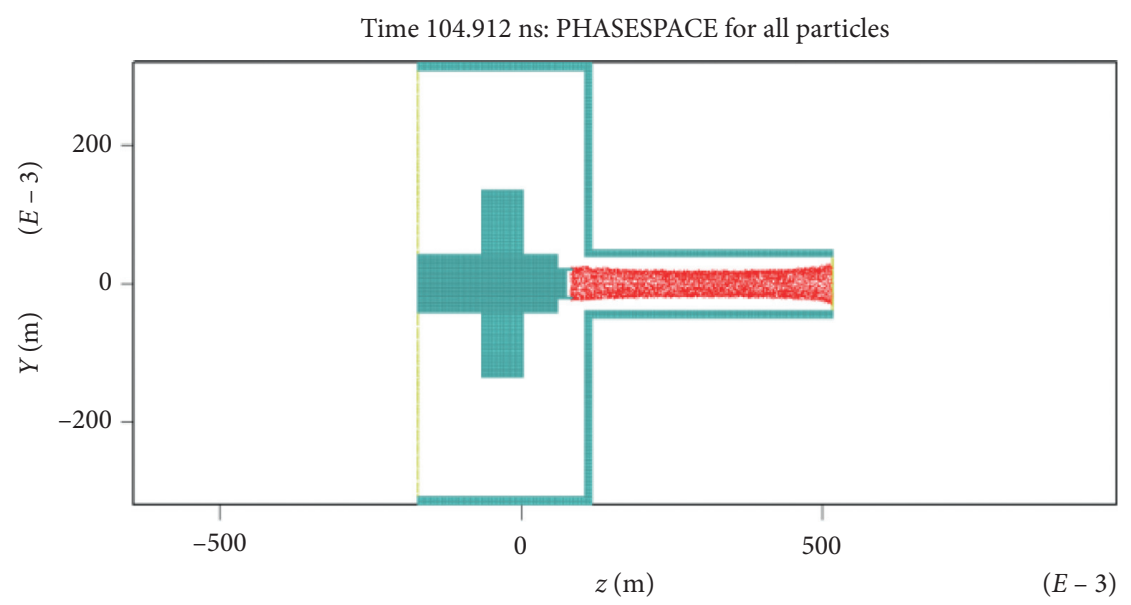

FIgure 10: The electrons trace guided by composite magnetic field.

field strength $1.4 \mathrm{~T}$, the transmission efficiency of the annular electron beam with voltage $590 \mathrm{kV}$ and current $2.6 \mathrm{kA}$ also achieves $100 \%$, and the diode impedance is $220 \Omega$. The output voltage and current waveforms of single pulse are shown in Figure 14. The beam image of single shot is also presented in Figure 14, the outer and inner diameters of the electron beam are $44 \mathrm{~mm}$ and $36 \mathrm{~mm}$, and the emission is uniform. 


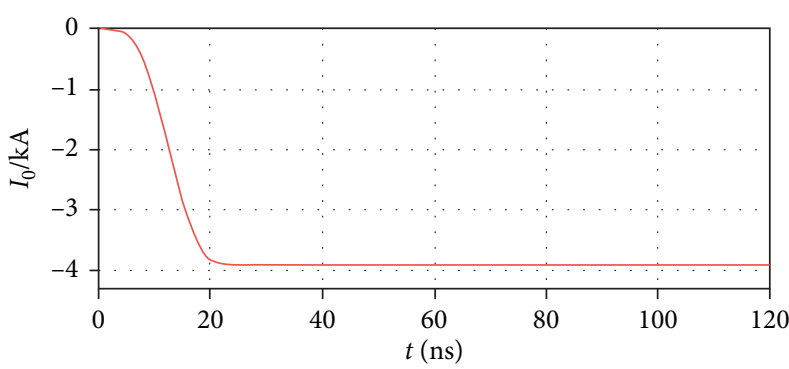

(a)

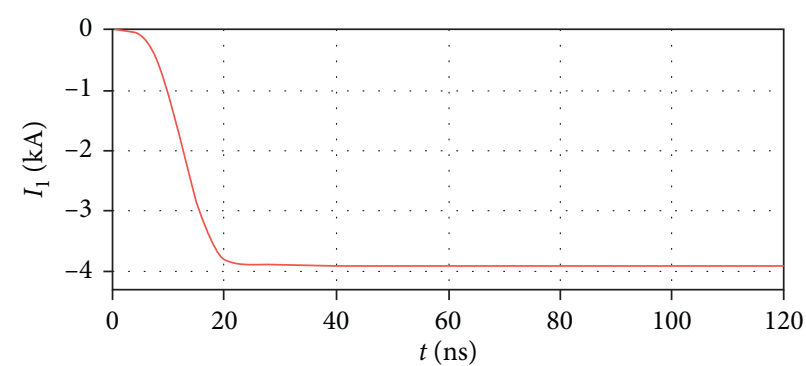

(b)

Figure 11: Waveforms of emitted current and received current: (a) the current waveform at the transmitter; (b) the current waveform at the receiver.

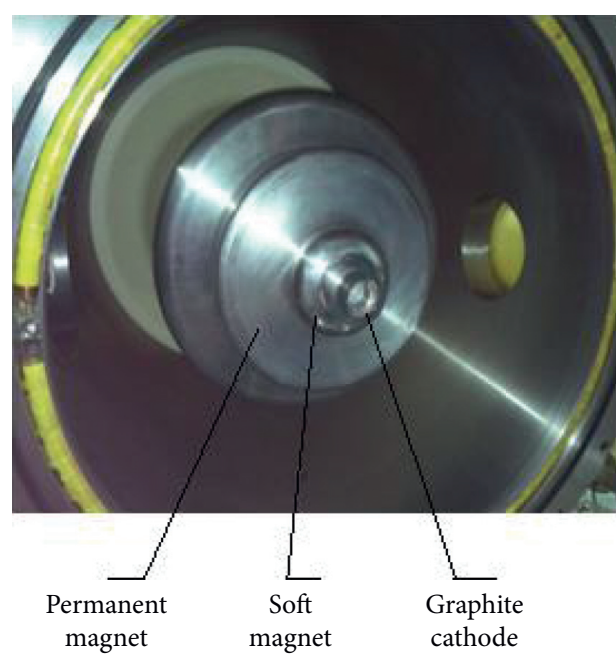

(a)

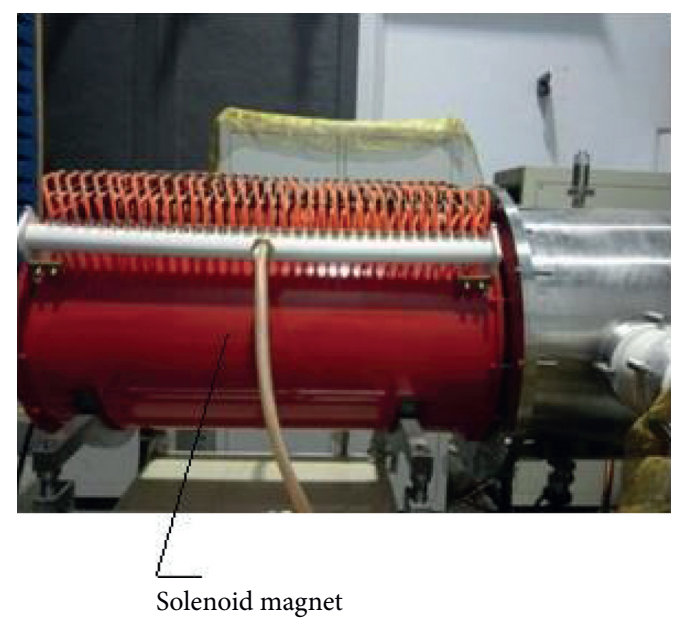

(b)

FIGURE 12: Developed foilless diode with composite magnetic field system.

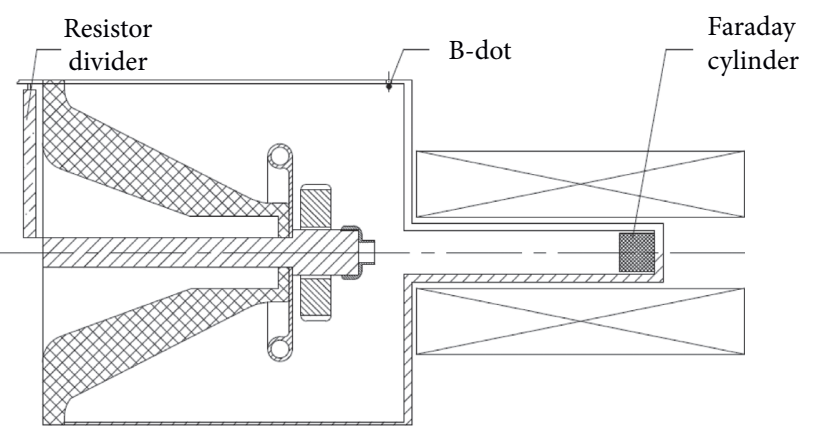

FIGURE 13: Configuration of voltage and current measurement devices. 

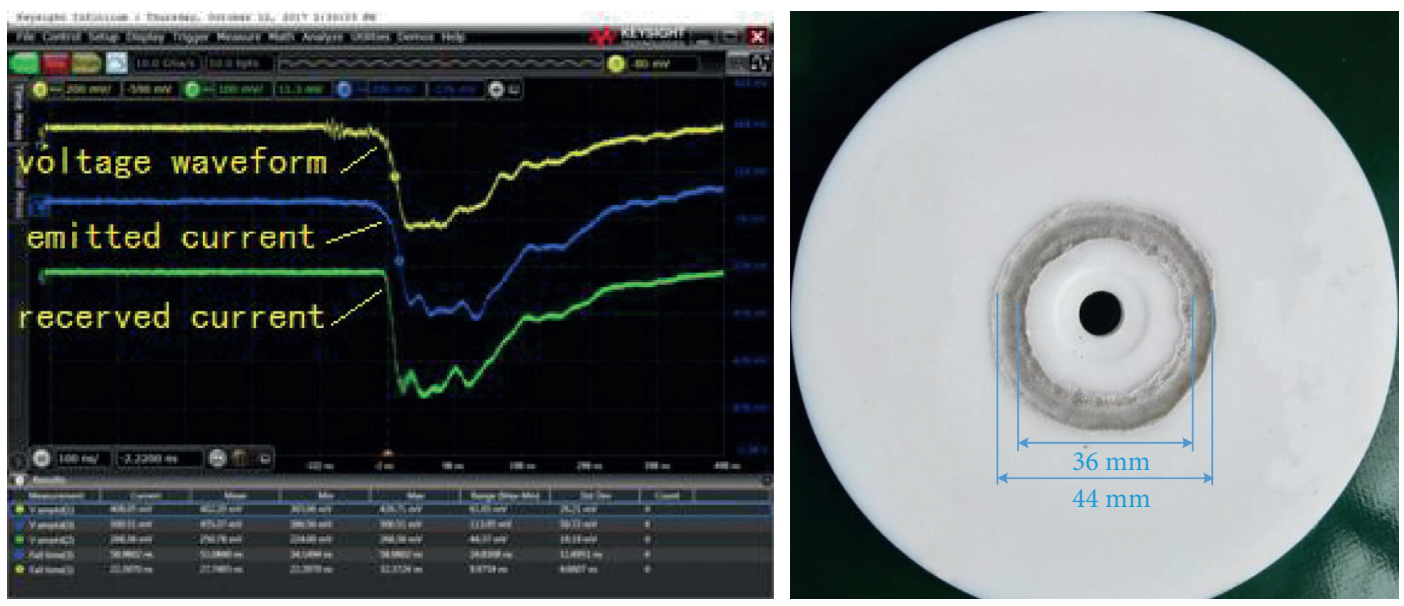

Figure 14: Output waveforms of single shot and the beam spot.

\section{Conclusion}

In this paper, a compact relativistic electron beam diode guided by composite magnetic field is proposed. By using the nonimmersion cathode structure, the inner diameter of the anode tube is reduced, and the radial emission of electrons on the cathode surface is suppressed. Moreover, the highefficiency transmission of electron beam is realized. The simulation and experimental results show that when the magnetic field strength of permanent magnet is $1.4 \mathrm{~T}$ and that of solenoid coil is in the range of $0.5 \mathrm{~T} \sim 1 \mathrm{~T}$, the transmission efficiency of electron beam can reach $100 \%$, and the impedance of diode can be adjusted in the range of $100 \Omega \sim 240 \Omega$.

The composite magnetic field system developed in this paper effectively utilizes the magnetic field at the end of the solenoid coil, giving full play to the advantages of permanent magnet and soft magnet. Under the condition of satisfying the magnetic field intensity required by electron beam transmission, the axial and radial dimensions of solenoid coil are shortened, and the miniaturization and lightweight of magnetic field system are realized. The volume, weight, and power consumption of the composite magnetic field system can be reduced by about $40 \%$ compared with the original system.

\section{Data Availability}

The data used to support the findings of this study are available upon request.

\section{Conflicts of Interest}

The authors declare that they have no conflicts of interest.

\section{References}

[1] S. D. Korovin, V. V. Rostov, S. D. Polevin et al., "Pulsed power-driven high-power microwave sources," Proceedings of the IEEE, vol. 92, no. 7, pp. 1082-1095, 2004.

[2] J. Zhang, X. Ge, J. Zhang et al., "Research progresses on Cherenkov and transit-time high-power microwave sources at
NUDT," Matter and Radiation at Extremes, vol. 1, no. 3, pp. 163-178, 2016.

[3] Y. Carmel and J. A. Nation, "Application of intense relativistic electron beams to microwave generation," Journal of Applied Physics, vol. 44, no. 12, pp. 5268-5274, 1973.

[4] A. Grossman, T. C. Marshall, and S. P. Schlesinger, "A new millimeter free electron laser using a relativistic beam with spiraling electrons," Physics of Fluids, vol. 26, no. 1, pp. 337-343, 1983.

[5] S. Robertson and A. Fisher, "Plasma heating by an electron beam from a foilless diode," Journal of Applied Physics, vol. 51, no. 8, pp. 4094-4096, 1980.

[6] M. Friedman, "A new diode for the production of high power relativistic electron beams," Review of Scientific Instruments, vol. 42, no. 8, pp. 1255-1256, 1971.

[7] M. Friedman and M. Ury, "Production and focusing of a high power relativistic annular electron beam," Review of Scientific Instruments, vol. 41, no. 9, pp. 1334-1335, 1970.

[8] A. A. Eltchaninov, B. M. Kovalchuk, I. K. Kurkan, and A. A. Zherlitsyn, "Foil-less plasma-filled diode for HPM generator," Journal of Physics: Conference Series, vol. 552, Article ID 012031, 2014.

[9] G. Z. Liu, Z. F. Yang, J. Sun, and Y. P. Zhang, "Characteristics of space-charge-limiting current for the magnetically immersed foilless diode," IEEE Transactions on Plasma Science, vol. 37, no. 10, pp. 2048-2054, 2009.

[10] F. Song, F. Li, B. Zhang, H. Gong, Y. Gan, and X. Jin, “A compact low jitter high power repetitive long-pulse relativistic electron beam source," Nuclear Instruments and Methods in Physics Research Section A: Accelerators, Spectrometers, Detectors and Associated Equipment, vol. 919, pp. 56-63, 2019.

[11] D. C. Straw and M. C. Clark, "Electron beams generated in foilless diodes," IEEE Transactions on Nuclear Science, vol. 26, no. 3, pp. 4202-4204, 1979.

[12] P. Wu, S. F. Huo, J. Sun, C. H. Chen, and G. Z. Liu, "Influence of emission threshold of explosive emission cathodes on current waveform in foilless diodes," Physics of Plasmas, vol. 22, no. 8, Article ID 083104, 2015.

[13] M. E. Jones and L. E. Thode, "Intense annular relativistic electron beam generation in foilless diodes," Journal of Applied Physics, vol. 51, no. 10, pp. 5212-5214, 1980.

[14] J. Sun, P. Wu, S. Huo et al., "Research on the emission uniformity of explosive emission cathodes in foilless diodes," 
IEEE Transactions on Plasma Science, vol. 42, no. 9, pp. 2179-2185, 2014.

[15] Y. Y. Lau, M. Friedman, J. Krall, and V. Serlin, "Relativistic Klystron amplifiers driven by modulated intense relativistic electron beams," IEEE Transactions on Plasma Science, vol. 18, no. 3, pp. 553-569, 1990.

[16] Y. Teng, T. Z. Liang, and J. Sun, "Generation of beating wave by multi-coaxial relativistic backward wave oscillator," Laser and Particle Beams, vol. 31, no. 4, pp. 703-714, 2013.

[17] R. Xiao, J. Sun, S. Huo et al., "Plasma expansion and impedance collapse in a foil-less diode for a klystronlike relativistic backward wave oscillator," Physics of Plasmas, vol. 17, no. 12, Article ID 123107, 2010.

[18] J. Zhang, Z.-X. Jin, J.-H. Yang et al., "Recent advance in longpulse HPM sources with repetitive operation in S-, C-, and X-bands," IEEE Transactions on Plasma Science, vol. 39, no. 6, pp. 1438-1445, 2011.

[19] J. A. Gaudet, R. J. Barker, C. J. Buchenauer et al., "Research issues in developing compact pulsed power for high peak power applications on mobile platforms," Proceedings of the IEEE, vol. 92, no. 7, pp. 1144-1165, 2004.

[20] F. Song, F. Li, B. Zhang et al., "Recent advances in compact repetitive high-power Marx generators," Laser and Particle Beams, vol. 37, no. 1, pp. 110-121, 2019.

[21] J. Jin, Z. Zhang, H. Yang et al., "Compact intense electronbeam accelerators based on high energy density liquid pulse forming lines," Matter and Radiation at Extremes, vol. 3, no. 6, pp. 278-292, 2018.

[22] Y. B. Cao, J. Sun, P. Wu et al., "Unexpected electric breakdown effects in a foilless diode," in Proceedings of the IEEE International Vacuum Electronics Conference, pp. 1-2, Beijing, China, April 2015.

[23] A. V. Gunin, V. F. Landl, S. D. Korovin, G. A. Mesyats, and V. V. Rostov, "Long-lived explosive-emission cathode for high-power microwave radiation generators," Technical Physics Letters, vol. 25, no. 11, pp. 922-926, 1999.

[24] R. Z. Xiao, X. W. Zhang, L. J. Zhang et al., "Efficient generation of multi-gigawatt power by a klystron-like relativistic backward wave oscillator," Laser and Particle Beams, vol. 28, no. 3, pp. 505-511, 2010. 